\title{
QUANTIFICAÇÃO DE BACTÉRIAS TOTAIS E ESPORULADAS NO SOLO'
}

\author{
Francisco Cleber Sousa Vieira²; Ely Nahas ${ }^{3 *}$ \\ ${ }^{2}$ Pós-Graduando do Programa em Biotecnologia - IQ/UNESP. \\ ${ }^{3}$ Depto. de Produção Vegetal - FCAV/UNESP, Rodovia Carlos Tonnani, km 5 - CEP: 14870-000 - Jaboticabal, SP. \\ *Autor correspondente <enahas@fcav.unesp.br>
}

\begin{abstract}
RESUMO: Este trabalho analisou o efeito da temperatura e período de incubação e da diluição do inóculo, em dois meios de cultura, sobre a quantificação de bactérias totais e esporuladas. O crescimento quantitativo e qualitativo de bactérias totais e esporuladas depende tanto do meio de cultura, temperatura, diluição e tempo utilizados como da interação desses fatores. O meio de TSA apresentou maior contagem que o meio de Thorton de unidades formadoras de colônias (UFC) de bactérias totais mas não de Bacillus spp. As colônias crescidas no meio de TSA apresentaram maior tamanho e forma mais nítida. $\mathrm{O}$ cultivo à temperatura de $30^{\circ} \mathrm{C}$ propiciou maior número de UFC que a $25^{\circ} \mathrm{C}$, sobretudo nos primeiros dias de incubação. $\mathrm{O}$ crescimento bacteriano correspondeu a uma equação de $3^{\circ}$ grau. Dependendo do meio de cultura, da temperatura de incubação e da diluição, os períodos de máximo crescimento foram de 4,9 a 6,9 dias para as bactérias totais e de 4,4 a 7,2 dias para Bacillus spp. Embora tenham sido utilizadas diluições decimais dos inóculos, as proporções entre as contagens variaram de 6,3 a 10,0 vezes para as bactérias totais e de 2,0 a 7,0 para as esporuladas.
\end{abstract}

Palavras-chave: Bacillus spp., bactérias totais, solo

\section{QUANTIFICATION OF TOTAL AND SPORULATING BACTERIA IN SOILS}

\begin{abstract}
This work studied the effect of the temperature and incubation time and of the inoculum dilution, in two culture media, on the quantification of total and sporulating bacteria. The quantitative and qualitative growth of total and sporulating bacteria depended on the growth medium, temperature, dilution and incubation time, as well as on the interaction of these factors. Tryptic Soil Agar medium presented a greater number of colony forming units (CFU) for total bacteria. However, for Bacillus spp. there were higher counts on Thorton medium. Colonies grown on Tryptic Soy Agar medium were of larger size and had a more clearly defined shape. An incubation temperature of $30^{\circ} \mathrm{C}$ yielded more CFU than incubation at $25^{\circ} \mathrm{C}$, especially during the first days of incubation. Bacterial growth was fit to a mathematical model and corresponded to a third degree equation. Depending on the growth culture medium, incubation temperature and dilution, periods of maximum growth were between 4.9 and 6.9 days for total bacteria and between 4.4 and 7.2 days for Bacillus spp. Although decimal inoculum dilutions were used, proportions between counts based on different conditions ranged from 6.3 to 10.0 times for total bacteria and from 2.0 to 7.0 times for sporulating bacteria.

Key words: Bacillus spp., total bacteria, soil
\end{abstract}

\section{INTRODUÇÃO}

Dos diversos métodos empregados para se avaliar o número de bactérias do solo, o mais utilizado baseia-se na contagem de colônias em placas de Petri, no qual se verifica uma significativa variação das condições utilizadas, basicamente o meio de cultura, a diluição do inóculo, a temperatura e o tempo de incubação. Assim, enquanto Richaume et al. (1993) determinaram o número de unidades formadoras de colônias (UFC) de bactérias de solo em placas de Petri, mantendo-as incubadas por 4 dias a temperatura de $25^{\circ} \mathrm{C}$, Acea \& Carballas (1990) empregaram a temperatura de $28^{\circ} \mathrm{C}$ e o período de incubação de 7 a 10 dias. Suwa \& Hattori (1984) utilizaram temperaturas intermediárias, isto é, de $26,5^{\circ} \mathrm{C}$ por 14 dias de incubação ou de $27^{\circ} \mathrm{C}$ por um período de uma semana. Para a determinação do número de Bacillus spp. esses autores incubaram as culturas por duas semanas na mesma temperatura. Ainda, temperaturas de $27-28^{\circ} \mathrm{C}$ e diferentes períodos de crescimento foram citados na literatura (Ishikuri \& Hattori, 1987; Balkwill \& Casida Junior, 1979; Schortemeyer et al., 1996) Temperaturas mais elevadas, de $30^{\circ} \mathrm{C}$, foram utilizadas por Aoki et al. (1995) e Watanabe \& Hayano (1995), por um período de uma semana, para a contagem e isolamento de Bacillus spp..

Temperaturas inferiores às citadas, isto é de 22$25^{\circ} \mathrm{C}$ foram utilizadas por Harris et al., 1995. Lynch \& Panting (1980), para avaliar o número de bactérias que se desenvolveram em meio de cultura ágar-extrato de malte, incubaram as placas de cultivo por 6 dias à temperatura de $25^{\circ} \mathrm{C}$. Uma temperatura de incubação ainda mais baixa, de $20^{\circ} \mathrm{C}$, foi utilizada por Olsson et al. (1996), porém com um período de incubação de 14 dias.

${ }^{1}$ Parte da Dissertação de Mestrado do primeiro autor apresentada ao Instituto de Química/UNESP - Araraquara, SP. 
Diferentes meios de cultura têm sido utilizados, onde a composição varia de salina, como os meios de Thorton e de Winogradsky, à complexa, como o meio de TSA (TABELA 1).

Pelo que se observa, as diferentes condições de cultivo empregadas para quantificar o número de bactérias do solo devem-se ao fato de haver uma diversidade microbiana, sendo praticamente impossível permitir que todos os microrganismos cresçam em uma única situação de cultivo (Kennedy \& Gewin, 1997). E, diferentes condições de crescimento permitem diferentes respostas de contagem. Contudo, poucos trabalhos têm levado em consideração as associações das condições de cultivo que influem no crescimento microbiano. Portanto, este trabalho analisou o efeito da temperatura e período de incubação e da diluição do inóculo, associados a dois meios de cultura, sobre a quantificação de bactérias totais e esporuladas.

\section{MATERIAL E MÉTODOS}

Solo: foi utilizada uma amostra de um Latossolo Vermelho-Escuro argiloso (composição: $P$ resina, 112 $\mathrm{mg} \mathrm{dm}^{-3}$; matéria orgânica, $26 \mathrm{mg} \mathrm{dm}^{-3} ; \mathrm{K}, 6,1 \mathrm{mmol}^{\circ}$ $\mathrm{dm}^{-3}$; $\mathrm{Ca}, 35 \mathrm{mmol}_{\mathrm{c}} \mathrm{dm}^{-3} ; \mathrm{Mg}, 12 \mathrm{mmol}_{\mathrm{c}} \mathrm{dm}^{-3} ; \mathrm{H}+\mathrm{Al}, 34$ $\left.\mathrm{mmol}_{\mathrm{c}} \mathrm{dm}^{-3} ; \mathrm{pH}\left(\mathrm{CaCl}_{2}\right), 5,4\right)$ que havia sido cultivado com sorgo granífero e que encontrava-se sem a presença de cultura agrícola no momento da amostragem. Foram coletadas 20 subamostras que foram reunidas em uma amostra composta, sendo então homogeneizada e estendida em uma bandeja para que se efetuasse a retirada de materiais estranhos, tais como pedaços de raízes e folhas, gravetos e outros. A amostra foi seca em estufa a $45^{\circ} \mathrm{C}$ por 5 dias e guardada em saco plástico até o momento de seu uso. Posteriormente, foi peneirada em peneira de malha de $2 \mathrm{~mm}$ (Olsen \& Bakken, 1987), reumedecida em aproximadamente $3 / 4$ da capacidade de campo (Kasahara \& Hattori, 1991) e incubada à temperatura de $30^{\circ} \mathrm{C}$ por 7 dias para equilibrar a população bacteriana. A umidade do solo foi medida gravimétricamente (p/p) (Vieira, 1995).

Contagem de microrganismos: Foram adicionados $10,0 \mathrm{~g}$ de solo a um Erlenmeyer contendo 95 $\mathrm{mL}$ de uma solução de pirofosfato de sódio $0,1 \%(\mathrm{p} / \mathrm{v})$. Após agitação por 30 minutos, em uma mesa agitadora, foram feitas diluições decimais em série, de $10^{-1}$ a $10^{-10}$. Em seguida, alíquotas de $0,1 \mathrm{~mL}$ de cada diluição foram transferidas pelo método "pour plate" em placas de Petri contendo meio de cultura. As placas foram acondicionadas em saco plástico com o objetivo de evitar o ressecamento do meio de cultura (Olsen \& Bakken, 1987; Sorheim et al., 1989) e incubadas em duas estufas BOD, com temperaturas a $30^{\circ} \mathrm{C}$ e a $25^{\circ} \mathrm{C}$, em ausência de luz. A temperatura de cada estufa de incubação foi verificada diariamente, utilizando-se, além do termômetro de cada estufa, um termômetro de máxima e mínima. As contagens foram feitas a cada 24 horas em um contador de colônias com $6 x$ de aumento, até não se constatar nenhum aumento do número de colônias. Foram consideradas apenas as contagens que variaram de 30 a 300 colônias (Clark , 1965; Schortemeyer et al., 1996).

Meios de cultura (Clark, 1965): Para as contagens das bactérias foram selecionados dois meios de cultura entre os citados na literatura, sendo um meio de composição complexa e um outro meio de composição salina, respectivamente os meios Tryptic Soy Agar (TSA Oxoid) e de Thorton (Sorheim et al., 1989). Para contagem de bactérias esporuladas (Bacillus spp.), submeteu-se o inóculo a um choque térmico, à temperatura de $80^{\circ} \mathrm{C}$ por 10 minutos, resfriando-o em seguida (Rothfuss et al., 1997).

TABELA 1 - Meios de cultura, temperatura e períodos de incubação utilizados para contagem de bactérias totais.

\begin{tabular}{lccl}
\hline Meios de cultura & $\begin{array}{c}\text { Temperaturas de } \\
\text { incubação }\end{array}$ & $\begin{array}{c}\text { Período de incubação } \\
\text { (dias) }\end{array}$ & Referência \\
\hline Plate count agar* & $20^{\circ} \mathrm{C}$ & 5 & Andersen \& Hirichsen, (1995) \\
Nutriente ágar+ágar solo & 15 a $20^{\circ} \mathrm{C}$ & 14 & Devlieg her \& Verstraete, (1995) \\
Thorton & $28^{\circ} \mathrm{C}$ & 7 & Cattelan \& Vidor, (1990) \\
Extrato de solo ágar & 22 a $25^{\circ} \mathrm{C}$ & 5 & Harris et al., (1995) \\
Ovo albumina ágar & $25^{\circ} \mathrm{C}$ & 14 & Kanazawa et al., (1986) \\
Nutriente ágar & $27^{\circ} \mathrm{C}$ & Até 7 & Kozdrój, (1995) \\
TSA & $28^{\circ} \mathrm{C}$ & 6 & Lawley et al., (1983) \\
Bunt \& Rovira & $30^{\circ} \mathrm{C}$ & 2 & Nahas et al., (1994) \\
Caseinato-ágar & $15^{\circ} \mathrm{C}$ & 7 a 14 & Linhares \& Drozdowicz, (1974) \\
TSA & $25^{\circ} \mathrm{C}$ & 10 & De Leij et al., (1993) \\
Winogradsky's & $22^{\circ} \mathrm{C}$ & 2 & Sorheim et al., (1989) \\
Plate count agar* & $21^{\circ} \mathrm{C}$ & 30 & Olsen \& Bakken, (1987)
\end{tabular}

${ }^{*}$ Meios prontos

Scientia Agricola, v.57, n.3, p.539-545, jul./set. 2000 
Delineamento Experimental: Foi utilizado um delineamento inteiramente casualizado, em fatorial, com três repetições (provenientes da amostra composta), constituído de três fatores (meio de cultura, diluição e temperatura de incubação), com o objetivo de comparar estimativas de variâncias dentro de cada período de incubação e, a análise de regressão polinomial para estudar o comportamento de cada condição de estudo no decorrer do período de incubação. Os resultados apresentados correspondem à média do número de colônias observado em cada dia de avaliação, tendo-se cinco placas de Petri para cada diluição utilizada. As contagens nas placas foram convertidas em UFC ${ }^{-1}$ solo seco e a seguir transformadas, antes da análise estatística, em $y=\log (x+1)$ em que $x$ corresponde ao número de UFC (Harris et al., 1995; Schortemeyer et al., 1996). Essa conversão é utilizada quando se pretende verificar a proporcionalidade entre as médias e desvios padrões dos diversos tratamentos.

\section{RESULTADOS E DISCUSSÃO}

A contagem de microrganismos do solo em placas de Petri mostra apenas uma parte da comunidade real existente neste ambiente. Devido ao fato de haver uma diversidade muito grande de microrganismos no solo, diferentes procedimentos podem ser utilizados para otimizar o crescimento microbiano e revelar número maior de espécies. Porém, quando se trabalha com um número grande de amostras e os resultados são exigidos em curto espaço de tempo, a técnica de diluição em placa de Petri torna-se um instrumento de grande utilidade. Portanto, as condições de cultivo, como por exemplo, o meio de cultura, a temperatura e o período de incubação devem ser escolhidas com cuidado (Sorheim et al., 1989). Além do mais, neste trabalho, ficou demonstrado que os fatores estudados isoladamente ou associados influenciaram o crescimento de bactérias totais e Bacillus spp..

Analisando-se o efeito do meio de cultura, verificase que os resultados das contagens diárias de bactérias totais variaram de 10 a $251,19 \times 10^{7} \mathrm{UFC} \mathrm{g}^{-1}$ solo seco no

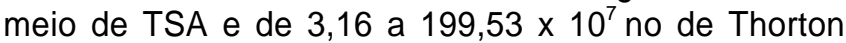
(TABELA 2). As contagens no meio de TSA foram superiores 1,3 a 1,6 vez às obtidas no meio de Thorton, quando se incubou as placas à temperatura de $30^{\circ} \mathrm{C}$ e de $1,3 \mathrm{a}$ 3,2 vezes a $25^{\circ} \mathrm{C}$. Maiores relações foram obtidas no início do período de incubação das placas, posteriormente as mesmas foram decrescendo. Além do meio complexo (TSA) permitir maior crescimento, as colônias foram maiores e mais nítidas.

A temperatura de incubação de $30^{\circ} \mathrm{C}$ também permitiu crescimento 1,3 a 1,6 vez maior das bactérias totais quando se comparou com a temperatura de $25^{\circ} \mathrm{C}$, em

TABELA 2 - Número de bactérias totais observadas nos diferentes tempos de contagens.

\begin{tabular}{|c|c|c|c|c|c|c|c|c|c|}
\hline \multirow{2}{*}{$\begin{array}{l}\text { Meio de } \\
\text { Cultura }\end{array}$} & \multirow[b]{2}{*}{ Diluição } & \multirow[b]{2}{*}{ Temp. } & \multicolumn{7}{|c|}{ Tempo de contagem (dias) } \\
\hline & & & 1 & 2 & 3 & 4 & 5 & 6 & $7 a 10$ \\
\hline & & & & & UFC $x$ & $107 \mathrm{~g}^{-1}$ solo & $0 \operatorname{seco}^{(1)}$ & & \\
\hline \multirow{4}{*}{ TSA } & $10^{-5}$ & $30^{\circ} \mathrm{C}$ & 15,80 & 31,60 & 39,80 & 39,80 & 39,82 & 39,82 & 39,82 \\
\hline & $10^{-6}$ & $30^{\circ} \mathrm{C}$ & 100,00 & 199,00 & 251,00 & 251,00 & 251,18 & 251,19 & 251,19 \\
\hline & $10^{-5}$ & $25^{\circ} \mathrm{C}$ & 10,00 & 25,00 & 31,60 & 39,80 & 39,81 & 39,81 & 39,81 \\
\hline & $10^{-6}$ & $25^{\circ} \mathrm{C}$ & 63,10 & 125,80 & 158,50 & 199,50 & 199,50 & 199,50 & 199,50 \\
\hline \multirow{4}{*}{ Thorton } & $10^{-5}$ & $30^{\circ} \mathrm{C}$ & 10,83 & 19,90 & 25,10 & 31,62 & 31,62 & 31,63 & 31,63 \\
\hline & $10^{-6}$ & $30^{\circ} \mathrm{C}$ & 79,40 & 158,40 & 199,50 & 199,50 & 199,52 & 199,53 & 199,53 \\
\hline & $10^{-5}$ & $25^{\circ} \mathrm{C}$ & 3,16 & 12,50 & 19,90 & 25,10 & 25,10 & 25,10 & 25,10 \\
\hline & $10^{-6}$ & $25^{\circ} \mathrm{C}$ & 31,60 & 79,40 & 125,00 & 125,88 & 125,90 & 125,92 & 125,92 \\
\hline \multicolumn{3}{|c|}{ Causa da variação } & \multicolumn{6}{|c|}{ Teste $\mathrm{F}$} & \\
\hline \multicolumn{3}{|c|}{ Meio de Cultura (A) } & $56,06^{\star *}$ & $45,69^{* *}$ & $68,06^{* *}$ & $31,03^{* *}$ & $31,03^{\star *}$ & $31,03^{\star *}$ & $31,03^{* *}$ \\
\hline \multicolumn{2}{|c|}{ Temperatura } & (B) & $28,06^{* *}$ & $45,84^{* *}$ & $39,75^{* *}$ & $61,40^{* *}$ & $61,40^{* *}$ & $61,40^{* *}$ & $61,40^{* *}$ \\
\hline \multicolumn{2}{|c|}{ Diluição } & (C) & $397,6^{\star *}$ & $807,9^{* *}$ & $2059,8^{* *}$ & $2123,1^{* *}$ & $2123^{* *}$ & $2123^{* *}$ & $2123^{* *}$ \\
\hline \multicolumn{3}{|l|}{$A \times B$} & $8,74^{* *}$ & $3,98 \mathrm{~ns}$ & $3,48 \mathrm{~ns}$ & $4,57^{*}$ & $4,57^{*}$ & $4,57^{*}$ & $4,57^{*}$ \\
\hline \multicolumn{3}{|l|}{$A \times C$} & $1,23 \mathrm{~ns}$ & $1,32 \mathrm{~ns}$ & $2,52 \mathrm{~ns}$ & $8,43^{*}$ & $8,43^{*}$ & $8,43^{*}$ & $8,43^{*}$ \\
\hline \multicolumn{3}{|l|}{$B \times C$} & $3,24 \mathrm{~ns}$ & $0,62 \mathrm{~ns}$ & $7,53^{*}$ & $1,34 \mathrm{~ns}$ & $1,34 \mathrm{~ns}$ & $1,34 \mathrm{~ns}$ & $1,34 \mathrm{~ns}$ \\
\hline \multicolumn{3}{|c|}{$A \times B \times C$} & $0,28 \mathrm{~ns}$ & $0,15 \mathrm{~ns}$ & $0,15 \mathrm{~ns}$ & $0,24 n s$ & $0,24 \mathrm{~ns}$ & $0,24 n s$ & $0,24 \mathrm{~ns}$ \\
\hline \multicolumn{3}{|c|}{ Coeficiente de variação (\%) } & 1,29 & 0,80 & 0,47 & 0,45 & 0,45 & 0,45 & 0,45 \\
\hline
\end{tabular}

(1) $\mathrm{N}^{\circ}$ de microrganismos observados no dia anterior $+\mathrm{n}^{\circ}$ de microrganismos observados no respectivo dia.

${ }^{\star *}=(p<0,01) ;{ }^{*}=(p<0,05) ; n s=$ não significativo

Teste F - calculado com base no log do $n^{\circ}$ de UFC $\mathrm{g}^{-1}$ de solo seco

Scientia Agricola, v.57, n.3, p.539-545, jul./set. 2000 
todas as condições, exceto no meio de Thorton, na diluição $10^{-6}$. Nesta situação, até o $3^{\circ}$ dia de incubação maiores contagens foram obtidas quando se empregou a temperatura de $25^{\circ} \mathrm{C}$. A partir do $4^{\circ}$ dia, não se notou diferença nas contagens.

Como era de se esperar, maior número de bactérias foi constatado nos inóculos mais diluídos das amostras de solo, contudo, não se constatou proporcionalidade nas contagens. Embora se tenha utilizado diluições decimais, as relações entre as respectivas contagens variaram de 5,0 a 10,0 vezes, sendo que maiores relações foram obtidas no meio salino de Thorton, no início do período de incubação. A TABELA 3 evidencia também que as contagens para cada meio de cultura foram dependentes da temperatura de incubação e da diluição $(p<0,05)$.
O efeito do tempo de incubação no crescimento das colônias pode ser apreciado pelos dados apresentados na TABELA 3. As primeiras colônias foram evidenciadas nas placas de Petri já no $1^{\circ}$ dia de incubação e o aparecimento de novas colônias foi verificado apenas até 0 $6^{\circ}$ dia de incubação, para todas as condições de cultivo. $O$ resultado desse crescimento obedeceu a uma equação de $3^{\circ}$ grau e mostrou que as maiores contagens foram obtidas entre 4,9 e 6,3 dias no meio de TSA e entre 4,9 e 6,9 dias no meio de Thorton.

$\mathrm{Na}$ TABELA 4 estão reunidos os dados de crescimento de Bacillus spp. isolados de solo em função das condições estudadas neste trabalho. Como se observa, as contagens variaram de 3,16 a 43,95 x 106 UFC $g^{-1}$ solo seco no meio de TSA e de 1,26 a 50,13 x

TABELA 3 - Períodos de máximo crescimento das bactérias totais.

\begin{tabular}{lcccccrr}
\hline Meio de cultura & Temperatura & Diluição & Equação de regressão & $\mathrm{R}^{2}$ & Tempo (dias) & UFC $^{*}$ \\
\hline \multirow{4}{*}{ TSA } & $30^{\circ} \mathrm{C}$ & $10^{-5}$ & $\mathrm{y}=-0,17+21,11 \mathrm{x}-3,39 \mathrm{x}^{2}+0,17 \mathrm{x}^{3}$ & 0,99 & 4,94 & 41,88 \\
& $30^{\circ} \mathrm{C}$ & $10^{-6}$ & $\mathrm{y}=-0,97+133,11 \mathrm{x}-21,36 \mathrm{x}^{2}+1,06 \mathrm{x}^{3}$ & 0,99 & 4,94 & 263,12 \\
& $25^{\circ} \mathrm{C}$ & $10^{-5}$ & $\mathrm{y}=-1,79+17,33 \mathrm{x}-2,30 \mathrm{x}^{2}+0,10 \mathrm{x}^{3}$ & 0,99 & 6,34 & 41,12 \\
& $25^{\circ} \mathrm{C}$ & $10^{-6}$ & $\mathrm{y}=-4,61+86,39 \mathrm{x}-11,65 \mathrm{x}^{2}+0,51 \mathrm{x}^{3}$ & 0,99 & 6,24 & 204,76 \\
\hline \multirow{4}{*}{ Thorton } & $30^{\circ} \mathrm{C}$ & $10^{-5}$ & $\mathrm{y}=-0,73+13,68 \mathrm{x}-1,84 \mathrm{x}^{2}+0,08 \mathrm{x}^{3}$ & 0,99 & 6,24 & 32,43 \\
& $30^{\circ} \mathrm{C}$ & $10^{-6}$ & $\mathrm{y}=-0,76+105,80 \mathrm{x}-16,98 \mathrm{x}^{2}+0,85 \mathrm{x}^{3}$ & 0,99 & 4,94 & 209,99 \\
& $25^{\circ} \mathrm{C}$ & $10^{-5}$ & $\mathrm{y}=-2,37+10,28 \mathrm{x}-1,20 \mathrm{x}^{2}+0,04 \mathrm{x}^{3}$ & 0,97 & 6,92 & 24,56 \\
\hline
\end{tabular}

* UFC g ${ }^{-1}$ solo seco $\times 10^{7}$

TABELA 4 - Número de Bacillus spp observados nos diferentes tempos de contagens.

\begin{tabular}{|c|c|c|c|c|c|c|c|c|c|}
\hline \multirow{2}{*}{ Meio de Cultura } & \multirow{2}{*}{ Diluição } & \multirow{2}{*}{ Temp. } & \multicolumn{7}{|c|}{ Tempo de contagem (dias) } \\
\hline & & & 1 & 2 & 3 & 4 & 5 & 6 & 7a 10 \\
\hline & & & \multicolumn{7}{|c|}{ UFC $\times 106 \mathrm{~g}^{-1}$ solo seco(1) } \\
\hline \multirow{4}{*}{ TSA } & $10^{-4}$ & $30^{\circ} \mathrm{C}$ & 5,01 & 7,94 & 10,00 & 10,00 & 10,03 & 10,03 & 10,00 \\
\hline & $10^{-5}$ & $30^{\circ} \mathrm{C}$ & 10,00 & 31,60 & 39,80 & 39,80 & 40,10 & 40,10 & 40,10 \\
\hline & $10^{-4}$ & $25^{\circ} \mathrm{C}$ & 3,16 & 6,31 & 6,70 & 7,17 & 7,17 & 7,17 & 7,17 \\
\hline & $10^{-5}$ & $25^{\circ} \mathrm{C}$ & 19,90 & 36,36 & 42,31 & 43,93 & 43,93 & 43,93 & 43,93 \\
\hline \multirow{4}{*}{ Thorton } & $10^{-4}$ & $30^{\circ} \mathrm{C}$ & 1,26 & 6,31 & 6,31 & 6,31 & 7,94 & 7,94 & 7,94 \\
\hline & $10^{-5}$ & $30^{\circ} \mathrm{C}$ & 10,00 & 31,60 & 39,80 & 50,10 & 50,13 & 50,13 & 50,13 \\
\hline & $10^{-4}$ & $25^{\circ} \mathrm{C}$ & 1,99 & 5,01 & 6,31 & 6,80 & 7,20 & 7,20 & 7,20 \\
\hline & $10^{-5}$ & $25^{\circ} \mathrm{C}$ & 10,00 & 31,60 & 39,80 & 50,10 & 50,10 & 50,10 & 50,10 \\
\hline \multicolumn{3}{|c|}{ Causa da variação } & \multicolumn{6}{|c|}{ Teste F } & \\
\hline Meio de Cultura & (A) & & $47,02 \mathrm{~ns}$ & $10,76^{* *}$ & $8,26^{*}$ & $2,59 \mathrm{~ns}$ & $2,59 \mathrm{~ns}$ & $2,59 \mathrm{~ns}$ & $2,59 \mathrm{~ns}$ \\
\hline Temperatura & (B) & & $1,06 \mathrm{~ns}$ & $1,66 \mathrm{~ns}$ & $8,21^{*}$ & $2,40 \mathrm{~ns}$ & $2,40 \mathrm{~ns}$ & $2,40 \mathrm{~ns}$ & $2,40 \mathrm{~ns}$ \\
\hline Diluição & (C) & & $209,5^{\star *}$ & $1072^{\star *}$ & $2252^{* *}$ & $2211^{* *}$ & $2211^{\star *}$ & $2211^{\star *}$ & $2211^{* *}$ \\
\hline$A \times B$ & & & $0,38 \mathrm{~ns}$ & $0,02 \mathrm{~ns}$ & $0,29 \mathrm{~ns}$ & $2,47 \mathrm{~ns}$ & $2,47 \mathrm{~ns}$ & $2,47 \mathrm{~ns}$ & $2,47 \mathrm{~ns}$ \\
\hline$A \times C$ & & & $8,35^{*}$ & $0,84 \mathrm{~ns}$ & $10,61^{* *}$ & $12,13^{* *}$ & $12,13^{* *}$ & $12,13^{* *}$ & $12,13^{* *}$ \\
\hline$B \times C$ & & & $1,84 \mathrm{~ns}$ & $8,62^{\star *}$ & $11,94^{* *}$ & $9,4^{* *}$ & $9,4^{* *}$ & $9,4^{* *}$ & $9,4^{* *}$ \\
\hline$A \times B \times C$ & & & $11,22^{* *}$ & $2,56 \mathrm{~ns}$ & $7,68^{*}$ & $5,99^{*}$ & $5,99^{*}$ & $5,99^{*}$ & $5,99^{*}$ \\
\hline Coeficiente de va & ariação (\%) & & 1,67 & 0,73 & 0,53 & 0,54 & 0,54 & 0,54 & 0,54 \\
\hline
\end{tabular}

(1) $\mathrm{N}^{\circ}$ de microrganismos observados no dia anterior $+\mathrm{n}$ - de microrganismos observados no respectivo dia.

${ }^{* *}=(p<0,01) ;{ }^{*}=(p<0,05) ; n s=$ não significativo 
$10^{6}$ no de Thorton, que correspondem, em média, a 2,5\% do total de bactérias totais observadas para este solo (dados não incluídos). No primeiro dia de incubação, foram observadas, dependendo da diluição utilizada, contagens de 1,0 a 4,0 vezes maiores no meio de TSA do que no de Thorton. Da mesma forma, no $1^{\circ} \mathrm{dia}$, as relações entre as contagens à temperatura de $30^{\circ} \mathrm{C}$ e $25^{\circ} \mathrm{C}$ variaram de 0,5 a 1,6, mostrando que em determinadas condições menor número de Bacillus spp. foram encontrados a $30^{\circ} \mathrm{C}$ que a $25^{\circ} \mathrm{C}$. A partir do $2^{\circ}$ dia de incubação, não se constatou influência nem do meio de cultura e nem da temperatura de incubação $(P<0,01)$ (TABELA 4).

$\mathrm{Da}$ mesma forma que as bactérias totais, observou-se efeito da diluição sobre as contagens, variando de 2,0 a 7,9 vezes a relação entre o inóculo mais diluído e o mais concentrado, sendo que no meio de TSA, à temperatura de $30^{\circ} \mathrm{C}$ foi encontrada menor relação, isto é, 2,0 a 4,0 vezes (TABELA 4).

Todas as interações dos fatores estudados foram estatisticamente significativas, exceto entre meio de cultura e temperatura. Esses resultados mostraram a influência do meio de cultura, da temperatura e da diluição sobre o número de Bacillus spp. crescidos em placa de Petri $(\mathrm{P}<0,01)$, (TABELA 4).

À semelhança das bactérias totais, os Bacillus spp. apresentaram curvas de crescimento ajustadas nas equações de $3^{\circ} \mathrm{grau}$ (TABELA 5). As primeiras colônias formadas em placas de Petri foram observadas com um dia de incubação contudo o aparecimento de novas colônias foi verificado apenas até o $5^{\circ}$ dia de incubação para todas as condições de cultivo. Os períodos em que o máximo crescimento foi verificado variaram de 4,8 a 7,2 dias, sendo que o meio de Thorton apresentou maior velocidade de crescimento que o de TSA.

O meio de TSA proporcionou maior número de colônias de bactérias totais quando comparado ao meio de Thorton, embora em muitos casos esta diferença tenha sido mínima. Contudo, a relação de crescimento nos dois meios de cultura foi maior no início do período de incubação e daí foi decrescendo até o último dia de contagem. A razão para essa diminuição do crescimento decorreu possivelmente das limitações encontradas tanto pela inibição pelo maior número de colônias favorecidas pelo meio de cultura complexo como pelo crescimento das colônias em meio salino. As colônias que cresceram no meio de TSA mostraram maior tamanho que as que cresceram no meio de Thorton, o que possibilitaria assim a melhor caracterização morfológica, bem como o isolamento das colônias. Martin (1975) não encontrou diferença significativa entre o crescimento nos meios de TSA e YPS (extrato de levedura, peptona e sais), embora este meio tenha apresentado maior número de colônias e, Richaume et al. (1993) também não encontraram diferença entre os meios de cultura TSA, nutriente ágar e ágar extrato de solo.

De forma geral, o número de colônias observado no cultivo à temperatura de incubação de $30^{\circ} \mathrm{C}$ foi superior ao obtido a $25^{\circ} \mathrm{C}$ nos meios de cultura empregados. Propriedade comum às reações químicas, o crescimento microbiano possui o comportamento de ativação pelo aumento da temperatura, como relatado por Scriban (1988), pois todas os processos de crescimento são dependentes de reações químicas que são afetadas pela temperatura (Pelczar Junior, 1996). Desta forma, era de se esperar que a maior temperatura de incubação apresentasse maior número de colônias que a menor temperatura empregada, com nenhuma ou pequenas diferenças estatísticas entre elas. Além do mais, cabe ressaltar que os grupos de microrganismos foram isolados de solos cuja temperatura média anual foi da ordem de $28^{\circ} \mathrm{C}$.

Dentro do critério estabelecido de considerar as contagens que apresentassem entre 30 e 300 colônias por placa, das diferentes diluições ensaiadas, pelo menos duas proporcionaram número de colônias entre estes limites, devido a não observação de proporções de dez vezes entre as diluições. É evidente, entretanto, que as maiores contagens de UFC foram obtidas nos inóculos mais diluídos, sendo os recomendados para quantificar o número de microrganismos em uma amostra de solo. No entanto, se a intenção for de estudar a variabilidade de bactérias em uma determinada amostra, diluições mais concentradas que proporcionem um maior número de colônias por placa seriam possivelmente as recomendadas.

TABELA 5 - Períodos de máximo crescimento de Bacillus spp.

\begin{tabular}{lcccccrr}
\hline Meio de cultura & Temperatura & Diluição & Equação de regressão & $R^{2}$ & Tempo (dias) & UFC $^{*}$ \\
\hline \multirow{4}{*}{ TSA } & $30^{\circ} \mathrm{C}$ & $10^{-4}$ & $y=0,31+5,26 x-0,86 x^{2}+0,04 x^{3}$ & 0,99 & 4,8 & 10,17 \\
& $30^{\circ} \mathrm{C}$ & $10^{-5}$ & $y=-2,11+21,34 x-3,33 x^{2}+0,16 x^{3}$ & 0,96 & 5,1 & 41,33 \\
& $25^{\circ} \mathrm{C}$ & $10^{-4}$ & $y=-0,28+2,75 x-0,36 x^{2}+0,02 x^{3}$ & 0,99 & 6,3 & 7,76 \\
\hline \multirow{4}{*}{ Thorton } & $25^{\circ} \mathrm{C}$ & $10^{-5}$ & $y=1,69+22,82 x-3,97 x^{2}+0,21 x^{3}$ & 0,95 & 4,4 & 43,13 \\
& $30^{\circ} \mathrm{C}$ & $10^{-4}$ & $y=-0,37+3,69 x-0,61 x^{2}+0,03 x^{3}$ & 0,90 & 4,8 & 6,61 \\
& $30^{\circ} \mathrm{C}$ & $10^{-5}$ & $y=-1,90+19,34 x-2,34 x^{2}+0,09 x^{3}$ & 0,98 & 7,2 & 49,63 \\
& $25^{\circ} \mathrm{C}$ & $10^{-4}$ & $y=-0,16+3,05 x-0,38 x^{2}+0,02 x^{3}$ & 0,98 & 7,2 & 9,57 \\
\hline
\end{tabular}

$\left.{ }^{*}\right)$ UFC g-1 solo seco $\times 10^{6}$ 
Mesmo com relações baixas entre as diluições das amostras de solo, na maioria dos casos foram observadas diferenças estatísticas significativas $(P<0,01)$ entre as contagens. Contudo, em momento algum houve proporcionalidade entre as diluições, como teoricamente deveria ocorrer. Porém, estas diferenças eram esperadas, uma vez que Egdell et al. (1960) também não encontraram relações proporcionais entre diluições $10^{-5}$ e $10^{-6}$, que foram de 1,5 a 2 vezes. Assim, estes autores citam que partículas de solo, agregados de células e diferenças de microlitros na diluição poderiam compor uma hipótese provável para a não observação de proporcionalidade entre as diluições. É possível considerar também que a dispersão de partículas de solo e de microrganismos proporcionada no inóculo mais diluído seja o efeito mais plausível para as maiores contagens.

Dependendo do meio de cultura utilizado, da temperatura de incubação e da diluição do inóculo, pelo menos um período de 4 a 7 dias deve ser adotado, que foi próximo ao empregado por Higashida \& Takao (1986), isto é, 7 dias de incubação à temperatura de $30^{\circ} \mathrm{C}$. $\mathrm{O}$ comportamento observado para o crescimento das bactéria totais e Bacillus spp. foi semelhante ao obtido por Hashimoto \& Hattori (1989). Embora se tenha evidenciado pequenas diferenças entre as contagens diárias, não significativas estatisticamente, há que se levar em consideração que as variações podem ser bastante expressivas. Por exemplo, na diluição $10^{-6}$ a $30^{\circ} \mathrm{C}$ e empregando-se o meio de TSA, obteve-se 251,00 $\times 10^{7}$ UFC $\mathrm{g}^{-1}$ de solo no $4^{\circ}$ dia de incubação e $251,18 \mathrm{x}$ $10^{7}$ no $5^{\circ}$ dia, portanto, 0,18 a mais que representam 1.800 .000 novas bactérias crescidas no período de 24 horas .

\section{CONCLUSÕES}

- A máxima contagem de bactérias de solo depende do meio de cultura e do tempo e temperatura de incubação das culturas.

- O maior número de UFC de bactérias totais foi obtido no meio de TSA, à temperatura de $30^{\circ} \mathrm{C}$ e após 5 dias de incubação, o de bactérias esporuladas foi no meio de Thorton à temperatura de $25^{\circ} \mathrm{C}$ e após 6,4 dias de incubação

\section{AGRADECIMENTOS}

À Fundação de Amparo à Pesquisa do Estado de São Paulo (FAPESP) e ao Conselho Nacional de Desenvolvimento Científico e Tecnológico (CNPq), pelas bolsas concedidas aos autores.

\section{REFERÊNCIAS BIBLIOGRÁFICAS}

ACEA, M.J.; CARBALLAS, T. Principal components analysis of the soil microbial population of humid zone of Galicia (Spain). Soil Biology and Biochemistry, v.22, p.749-759, 1990.
ANDERSEN, H.J.; HINRICHSEN, L.L. Changes in curing agents, microbial counts and volatile compounds during procesing of green bacon using two different production technologies. Journal of the Science of Food and Agriculture, v.68, p.477-487, 1995.

AOKI, K.; MIYAMOTO, K.; MURAKAMI, S.; SHINKE, R. Anaerobic synthesis of extracellular proteases by the soil bacterium Bacillus sp. AM-23: purification and characterization of the enzymes. Soil Biology and Biochemistry, v.27, p.1377-1382, 1995.

BALKWILL, D.L.; CASIDA JUNIOR, L.E. Attachment to autoclaved soil of bacterial cells from pure cutures of soil isolates. Applied and Environmental Microbiology, v.37, p.1031-1037, 1979.

CATTELAN, A.J.; VIDOR, C. Sistemas de cultura e a população microbiana do solo. Revista Brasileira de Ciência do Solo, v.14, p.125-132, 1990.

CLARK, F.E. Agar-plate method for total microbial count. In: BLACK, C.A.; EVANS, D.D.; ENSMINGER, L.E.; WHITE, J.L.; CLARK, F.E. Methods of soil analysis. Madison: American Society of Agronomy, 1965. v.2, p.1460-1466. (ASA, 9).

DE LEIJ, F.A.A.M.; WHIPPS, J.M.; LYNCH, J.M. The use of colony development for the characterization of bacterial communities in soil and on roots. Microbial Ecolology, v.27, p.81-97, 1993.

DEVLIEGHER, W.; VERSTRAETE, W. Lumbricus terrestris in a soil core experiment: nutrient-enrichment processes (NEP) and gut-associated processes (GAP) and their effect on microbial biomass and microbial activity. Soil Biology and Biochemistry, v.27, p.1573-1580, 1995.

EGDELL, J.W.; CUTHBERT, W.A.; SCARLETT, C.A.; THOMAS, S.B.; WESTMACOTT, M.H.; BIRD, E.R. HARRISON, J. Some studies of the colony count technique for soil bacteria. Journal of Applied Bacteriology, v.23, p.69-86, 1960.

HARRIS, P.A.; SCHOMBERG, H.H.; BANKS, P.A.; GIDDENS, J. Burning, tillage and herbicide effects on the soil microflora in a wheat-soybean double-crop system. Soil Biology and Biochemistry, v.27, p.153-156, 1995.

HASHIMOTO, T.; HATTORI, T. Grouping of soil bacteria by analysis of colony formation on agar plates. Biology and Fertility of Soils, v.7, p.198-201, 1989.

HIGASHIDA, S.; TAKAO, K. Relations between soil microbial activity and soil properties in grassland. Soil Science and Plant Nutrition, v.32, p.587-597, 1986.

ISHIKURI, S.; HATTORI, T. Analysis of colony forming curves of soil bacteria. Soil Science and Plant Nutrition, v.33, p.355-362, 1987.

KANAZAWA, S.; TAKESHIMA, S.; OHTA, K. Effect of waring blender treatment on the counts of soil microorganisms. Soil Science and Plant Nutrition, v.32, p.81-89, 1986.

KASAHARA, Y.; HATTORI, T. Analysis of bacterial populations in a grassland soil according to rates of development on solid media. FEMS Microbiology Ecology, v.86, p.95-102, 1991.

KENNEDY, A.C.; GEWIN, V.L. Soil microbial diversity: present and future considerations. Soil Science, v.162, p.607-617, 1997.

KOZDRÓJ, J. Microbial responses to single or successive soil contamination wiht $\mathrm{Cd}$ or $\mathrm{Cu}$. Soil Biology and Biochemistry, v.27, p.1459-1465, 1995

LAWLEY, R.A.; CAMPBELL, R.; NEWMAN, E.I. Composition of the bacterial flora of the rhizosphere of three grassland plants grown separately and in mixtures. Soil Biology and Biochemistry, v.15, p.605-607, 1983.

LINHARES, L.F.T.L.; DROZDOWICZ, A. Atividade microbiológicas de solos radioativos. Revista de Microbiologia, v.5, p.43-48, 1974.

LYNCH, J.M.; PANTING, L.M. Cultivation and the soil biomass. Soil Biology and Biochemistry, v.12, p.29-33, 1980. 
MARTIN, J.K. Comparison of agar media for counts of viable soil bacteria. Soil Biology and Biochemistry, v.7, p.401-402, 1975.

OLSEN, R.A.; BAKKEN, L.R. Viability of soil bacteria: optimization of plate counting technique and comparison between total counts and plate counts winthin different size groups. Microbial Ecology, v.13, p.59-74, 1987.

OLSSON, P. A.; BAATH, E.; JAKOBSEN, I.; SODERSTROM, B. Soil bacteria respond to presence of roots but not to mycelium of arbuscular mycorrhizal fungi. Soil Biology and Biochemistry, v.28, p.463-470, 1996.

PELCZAR JUNIOR., J. M. Microbiologia: conceitos e aplicações. 2.ed. São Paulo: Makron Books, 1996. 524 p.

RICHAUME, A.; STEINBERG, C.; JOCTEUR-MONROZIER, L.; FAURIE, G. Differences between direct and indirect enumeration of soil bacteria: the influence of soil structure and cell location. Soil Biology and Biochemistry, v.25, p.641-643, 1993.

ROTHFUSS, F.; BENDER, M.; CONRAD, R. Survival and activity of bacteria in a deep, aged lake sediment (lake constance). Microbial Ecology, v.33, p.69-77, 1997.

SCHORTEMEYER, M.; HARTWIG, U.A.; HENDREY, G.R.; SADOWSKY, M.J. Microbial community changes in the rhizospheres of white clover and perennial ryegrass exposed to free air carbon dioxide enrichment (face). Soil Biology and Biochemistry, v.28, p.1717-1724, 1996.
SCRIBAN, R. Biotecnologie. 3.ed. Paris: Technique et Documentation Lavoisier, 1988. 906p.

SORHEIM, R.; TORSVIK, V.L.; GOKSOYR, J. Phenotypical divergences between populations of soil bacteria isolated on different media. Microbial Ecology, v.17, p.181-192, 1989.

SUWA, Y.; HATTORI, T. Effects of nutrient concentration on the growth of soil bacteria. Soil Science and Plant Nutrition, v.30, p.397-403, 1984.

VIEIRA, F.C.S. Microrganismos e atividade microbiana em latossolo submetido a diferentes condições de conservação. Jaboticabal, 1995. 50p. Monografia (Graduação) - Faculdade de Ciências Agrárias e Veterinárias de Jaboticabal, Universidade Estadual Paulista "Julio de Mesquita Filho".

WATANABE, K.; HAYANO, K. Seasonal variation of soil protease activities and their relation to proteolytic bacteria and Bacillus spp. in paddy field soil. Soil Biology and Biochemistry, v.27, p.197-203, 1995.

$\overline{\text { Recebido em } 16.04 .99}$ 